\title{
DIREITOS HUMANOS DOS PACIENTES E VULNERABILIDADE: O PACIENTE IDOSO A LUZ DA JURISPRUDENCIA DA CORTE EUROPEIA DE DIREITOS HUMANOS
}

\author{
Aline Albuquerque ${ }^{1}$ \\ Denise G.A.M. Paranhos ${ }^{2}$
}

\begin{abstract}
Resumo
Este artigo tem o objetivo de examinar as interfaces entre vulnerabilidade e direitos humanos, particularmente a correlação do primeiro conceito com os Direitos Humanos dos Pacientes, entendidos, neste estudo, como referencial teórico-normativo que trata da incidência das normas de direitos humanos à esfera dos cuidados em saúde. Assim, além de traçar os contornos teóricos da correlação entre direitos humanos e vulnerabilidade, com particular atenção aos pacientes, também se objetivou investigar como uma corte de direitos humanos aplica na prática tais direitos sob o enfoque da vulnerabilidade específica do paciente idoso. Sob o prisma metodológico, trata-se de pesquisa de cunho bibliográfico e documental. Concluiu-se que há que se harmonizar o reconhecimento da vulnerabilidade acrescida do paciente idoso com o dever de respeitar suas escolhas, desejos e emoções; desqualifica-los em razão de ideias que sustentam sua incapacidade cognitiva decorrente dos efeitos do envelhecimento sobre o cérebro não é aceitável do ponto de vista dos direitos humanos. Por fim, reconhece-se que a alteração desse sentido social demanda árduo trabalho na formação dos profissionais de saúde, de modo que seus estudos de graduação também contemplem uma compreensão ética do outro, mediante a incorporação da linguagem dos direitos humanos ao seu arcabouço profissional.
\end{abstract}

Palavras-chave: direitos humanos; vulnerabilidade; paciente; idoso.

\section{INTRODUÇÃO}

A partir da segunda metade do século XX, verifica-se o surgimento dos direitos dos pacientes, impulsionado pela confluência de movimentos reivindicatórios de direitos civis, particularmente das mulheres e

\footnotetext{
${ }^{1}$ Pós-Doutorado em Direitos Humanos e Pesquisadora Visitante do Centro de Direitos Humanos da Universidade de Essex, Inglaterra. Pós-Doutorado em Direito Humano à Saúde e Pesquisadora Visitante no Instituto de Direitos Humanos da Universidade de Emory, Estados Unidos. Professora Credenciada da Pós-Graduação em Bioética da Universidade de Brasília e do Curso de Especialização em Bioética da Cátedra UNESCO de Bioética. Membro do CBEC. Professora de Direitos Humanos do UniCEUB. Professora do Curso de Especialização em Direito Médico da UERJ, do Curso de Especialização em Direito Sanitário da FIOCRUZ. Professora de Direitos Humanos da Pós-Graduação do UniCEUB. Pesquisadora Associada do Núcleo de Diplomacia e Saúde da FIOCRUZ.E-mail: alineaoliveira@hotmail.com

2 Doutoranda em Bioética pela Universidade de Brasília - Cátedra Unesco. Especialista em Direito Tributário pela Pontifícia Universidade Católica de Goiás. Bacharel em Direito pela Universidade Federal de Goiás. Analista Judiciário da Justiça Federal Seção Judiciária de Goiás. E-mail: paranhos.denise@uol.com.br
} 
dos consumidores. Tais movimentos contestaram o paternalismo médico e postularam o direito sobre o próprio corpo, acarretando, assim, a formação de ativismos em torno da ideia de que os pacientes não se encontram subjugados à deliberação médica, e, que, consequentemente, detêm direito de se autodeterminar. O próprio sentido etimológico da palavra "paciente" traduz a ideia de vulnerabilidade, nomina aquele que se encontra em situação de fragilidade, porquanto o termo se origina do vocábulo em latim "patior", que significa suportar ou sofrer (ANDORNO, 2016). Desse modo, o paciente foi considerado até a década de setenta do século XX tão somente um receptor de cuidados, que, em razão de sua enfermidade, não tinha condições de participar ativamente de seu processo terapêutico. Assim, a condição de particular fragilidade do paciente era tomada como justificante da mitigação de sua vontade quanto ao seu tratamento, o que conduz ao corolário equivocado de que a fragilidade de alguém impõe restrição de sua autonomia. Em contraposição a tal ilação, o arsenal internacional teórico-normativo dos direitos humanos, também a datar de meados do século passado, foi sendo empregado como instrumental apto a alterar a concepção de que o paciente é incapaz de deliberar em razão de sua fragilidade, fornecendo substrato para advogar sua autonomia.

Nesse sentido, embora o discurso dos direitos humanos reconheça, apoie e, em alguma medida, se fundamente na ideia de vulnerabilidade, distintamente da visão tradicionalista, isso não impele à negação da autonomia do paciente ou de qualquer outro indivíduo vulnerável. Distintamente, o fato de se associar a vulnerabilidade, como condição intrínseca dos seres humanos, aos direitos, traz à tona a acepção de que as pessoas são vulneráveis, umas mais e outras menos, e, que por isso, cabe à sociedade criar instituições para protegê-las. Entretanto, essa proteção não se confunde com paternalismo, mas sim é entendida, neste artigo, como meio de estimular a autonomia e o direito de conduzir sua vida conforme suas próprias escolhas e sua ideia de bem. Portanto, neste artigo, tem-se o objetivo de examinar os modos de confluência entre vulnerabilidade e direitos humanos, particularmente a correlação do primeiro conceito com os Direitos Humanos dos Pacientes, entendidos, neste estudo, como referencial teórico-normativo que trata da incidência das normas de direitos humanos à esfera dos cuidados em saúde, conforme Albuquerque (2016).

Assim, além de traçar os contornos teóricos da correlação entre direitos humanos e vulnerabilidade, com particular atenção aos pacientes, também se objetivou investigar como uma corte de direitos humanos aplica na prática tais direitos sob o enfoque da vulnerabilidade específica do paciente idoso. Desse modo, optou-se por enfocar os pacientes idosos em razão do amplo reconhecimento das pessoas idosas como um grupo vulnerável (GROVER, 2011). Conforme assinala Elias (2001, p.83), o processo de envelhecimento "produz uma mudança fundamental na posição de uma pessoa na sociedade, e, portanto, em todas as suas relações com os outros". Com efeito, a pessoa idosa não é considerada particularmente vulnerável apenas em razão de fatores fisiológicos, como os que tornam o corpo envelhecido "vagaroso, cansado e desajeitado" (ELIAS, 2001, p.80), mas também o 
sentido socialmente partilhado acerca do paciente idoso que, comumente, o concebe como incapaz para tomar suas próprias decisões. Tal sentido social repercute na área da saúde, por exemplo, há inúmeros relatos de profissionais de saúde que não obtêm o consentimento do paciente idoso de forma adequada, tão somente em razão de sua particular condição (GROVER, 2011). Assim, se, comumente, tem-se o entendimento de que o paciente por ser vulnerável tem seus direitos humanos limitados, quanto ao paciente idoso, essa errônea visão se agrava.

Considerando, então, a relevância da temática ora exposta que implica a expansão da ideia de que pacientes são vulneráveis, porém tal condição não conduz à redução da sua autonomia, e, conseguintemente, à restrição de direitos humanos, este estudo tem como escopo analisar a particular condição de vulnerabilidade de pacientes e as repercussões de tal fato no exercício de sua autonomia.

Sob o prisma metodológico, trata-se de pesquisa de cunho bibliográfico e documental, ancorada em estudos desenvolvidos no campo dos direitos humanos. Quanto ao marco teórico empregado, foram utilizados os estudos de Andorno (2016), Herring (2016), Butler (2015), Turner (2006) e Albuquerque (2016). No que tange à pesquisa documental, levou-se a cabo o levantamento de decisões da Corte Europeia de Direitos Humanos, atinentes aos cuidados em saúde de pacientes idosos, contidas em seu Factsheet ${ }^{3}$ sobre pessoa idosa (CORTE EUROPEIA DE DIREITOS HUMANOS, 2016). Dos trinta e dois casos reportados no documento ao tempo da pesquisa, foram analisados apenas aqueles em que o idoso era paciente, ou seja, não foram apreciadas outras violações de direitos humanos contidas no Factsheet que não tivessem relação com ofensas sofridas por pacientes idosos no contexto dos cuidados em saúde. Escolheu-se a Corte Europeia em razão de ser a única Corte de Direitos Humanos que conta com jurisprudência sobre o tema objeto deste estudo. Assim, embora o Brasil não se submeta juridicamente à Corte Europeia, a sua abordagem se mostra importante por ser o único órgão jurisdicional de direitos humanos a tratar robustamente de temas relacionados aos Direitos Humanos dos Pacientes (ALBUQUERQUE, 2016). Em seguida, passa-se à interface entre direitos humanos e vulnerabilidade.

\section{INTERFACES ENTRE DIREITOS HUMANOS E VULNERABILIDADE}

A correlação entre os direitos humanos e a vulnerabilidade será abordada com base em três autores que enfocam em suas pesquisas essa temática: Andorno (2016); Herring (2016); e Turner (2006). Ainda, serão trazidas algumas reflexões sobre a vulnerabilidade feitas por Butler (2015). Sendo assim, considerando a variabilidade de conceitos de "vulnerabilidade", importa enunciar de qual concepção se parte neste estudo. Com efeito, o termo "vulnerabilidade" é empregado em contextos distintos com diferentes significados, bem como

\footnotetext{
${ }^{3}$ O Factsheet é um documento produzido pela Corte Europeia de Direitos Humanos que contém a coletânea de decisões relevantes sobre temas específicos.
} 
campos do saber variados o utilizam a partir de compreensão própria. Herring (2016) pontua que no plano acadêmico há duas vertentes sobre a definição de "vulnerabilidade": a primeira enfatiza a vulnerabilidade humana universal e a segunda sustenta que alguns grupos ou pessoas devem ser vistos como vulneráveis. Em consonância com o entendimento de Herring (2016), neste artigo advoga-se que as duas vertentes se compatibilizam, como adiante será demonstrado.

Todas as pessoas são vulneráveis e tal condição implica ser frágil e suscetível de sofrer um dano, físico ou psíquico, o que atinge a todos, indistintamente. Logo, a condição de vulnerável é ontologicamente intrínseca à humanidade (HERRING, 2016). A vulnerabilidade humana deriva do fato de que os seres humanos são essencialmente gregários, assim, um ser depende do outro para a manutenção do seu bem-estar físico e psíquico, bem como se expõem mutuamente (BUTLER, 2015). Assim, desde o nascimento, os seres humanos constroem sua identidade a partir da interação com o outro, a interdependência é uma característica inconteste das relações humanas, que se interconecta com a precariedade da vida, conceito elaborado por Butler (2015), na medida em que exprime o fato de que nossas vidas, em alguma medida, estão nas mãos do outro.

No que tange aos critérios para aferir a vulnerabilidade, segundo Herring (2016), uma pessoa é vulnerável se três fatores estão presentes: a) se encontra diante de risco de dano; b) não detém recursos para evitar que o risco de dano se materialize; c) não teria meios adequados para responder ao dano, caso o risco se materializasse. Schroeder e Gefenas (apud HERRING, 2016) argumentam que vulnerabilidade é estar exposto à possibilidade de dano, elemento externo, e estar substancialmente inapto a se proteger de tal possibilidade, que seria seu elemento interno. Distintamente, para Herring (2016), ao rechaçar os elementos interno e externo, o ponto central da caracterização da vulnerabilidade recai sobre o risco de dano e as habilidades individuais para evita-lo. Butler (2015) vai além da afirmação da eventualidade de dano como elemento caracterizador da vulnerabilidade, pois traz à tona a ideia de precariedade da vida, que reflete a ideia de que se está exposto às ações e às omissões de conhecidos e desconhecidos (BUTLER, 2015). Assim, a vida humana é ontologicamente precária em razão de estarmos incondicionalmente vinculados ao outro e de não termos controle absoluto sobre esse outro.

A concepção de vulnerabilidade universal se conjuga com a percepção empírica de que determinados grupos de pessoas ou indivíduos apresentam uma condição de vulnerabilidade acrescida, até mesmo porque a assertiva de que todos são vulneráveis não significa que sejam igualmente vulneráveis (HERRING, 2016). Nesse sentido, Collins (apud HERRING, 2016) sustenta a ideia de que vulnerabilidade universal pode minar os fundamentos que ancoram políticas públicas e a alocação de recursos destinados a conferir especial proteção a grupos específicos. Sendo assim, é importante enfatizar que a vulnerabilidade ontológica se conjuga com a específica. 
De acordo com Herring (2016), o incremento da vulnerabilidade de certos grupos não é inato a tais pessoais, na medida em que decorre do suporte econômico, social e institucional disponível para atender às necessidades de tais grupos. Desse modo, se determinado grupo é mais vulnerável isso não se dá em razão de uma característica que lhe é intrínseca, mas sim decorre da alocação ou não de suporte social. No mesmo sentido, Butler (2015) atrela a noção de precariedade da vida às condições sociais e políticas nas quais se desenvolve, apartando-se, assim, de uma concepção atomizada, entretanto, enfatiza que "nem todas as formas de precariedade são produzidas por arranjos políticos e sociais" (BUTLER, 2015, p.86). Este artigo não se propõe a debater as razões que originam vulnerabilidades específicas ou acrescidas, contudo, importa registrar que, não obstante avalizar o entendimento de Herring (2016) acerca da inegável importância das redes de proteção para mitigar barreiras ou criar oportunidades com vistas a enfrentar situações particulares, este estudo sustenta que o paciente, a despeito da existência de maior ou menor suporte social, apresenta vulnerabilidade específica intrínseca à sua condição. Ademais, tal condição, por óbvio, varia de grau em razão da enfermidade, do estado emocional do paciente, do local onde se encontra, isto é, se em casa ou hospitalizado, bem como em decorrência do suporte social.

Desse modo, demarcada a acepção de vulnerabilidade adotada neste artigo, isto é, os conceitos de vulnerabilidade universal e específica, bem como os modos de sua caracterização, quais sejam o risco de dano a que se está sujeito inexoravelmente e a precariedade da vida, passa-se ao exame da correlação entre vulnerabilidade e direitos humanos. Com efeito, o entendimento de Turner (2006) sobre direitos humanos parte da vulnerabilidade humana, enquanto condição ontológica do humano (HERRING, 2016). Nesse sentido, Turner (2006) sustenta que nossa comum vulnerabilidade é o fundamento dos direitos humanos, porquanto os seres humanos sentem dor e sofrem por serem vulneráveis. A experiência da dor e do sofrimento ultrapassa diferenças culturais e de outras ordens, revelando ser um solo comum para se alicerçar o edifício dos direitos humanos. A vulnerabilidade universal, decorrente da precariedade da vida e da fragilidade humana, impõe a necessidade de construir determinados comandos normativos ético-jurídicos que objetivem mitigar o sofrimento e a dor, os quais são traduzidos nos "direitos humanos". Considerando que os seres humanos são interdependentes e que essa condição lhes coloca em situação de fragilidade, na medida em que não se controla absolutamente o outro, não se mostra possível, na história da humanidade, a proteção individual para a mitigação da vulnerabilidade, ou seja, os seres humanos sempre buscaram modos coletivos de enfrenta-la. Assim, a criação de instituições sociais e de arranjos políticos e morais, dentre esses os direitos humanos, deriva da necessidade humana de proteção, que se origina da vulnerabilidade ontológica (TURNER, 2006).

A sociedade é composta por instituições, como instituições culturais, familiares e políticas, com vistas não apenas a organizar a vida humana, mas também, e, precipuamente, a permitir mútua colaboração, permeada 
por sentimentos de empatia, simpatia e confiança, sem os quais a vida humana não teria condições de se desenvolver. As instituições são constituídas para mitigar a vulnerabilidade e nos dar segurança (TURNER, 2006), e, além delas, os seres humanos desenvolveram ideias amplamente compartilhadas que propiciam a coesão das sociedades e, em consequência, a colaboração entre conhecidos e desconhecidos. Essas ideias intersubjetivas são criadas por grupos humanos e fomentam o sentimento de pertencimento, de empatia, de identificação, dentre outros fundamentais para a atuação colaborativa. Dentre essas criações humanas, estão os direitos humanos. Desse modo, os direitos humanos são invenções humanas historicamente construídas com a finalidade de aprimorar a vida em sociedade por meio da proteção dos seres humanos, de sua vulnerabilidade intrínseca (TURNER, 2006).

Embora se admita a plausibilidade teórica da fundamentação dos direitos humanos na vulnerabilidade universal sustentada por Turner (2006), há que se reconhecer que no âmbito dos Sistemas Internacionais de Proteção dos Direitos Humanos, como o Sistema da Organização das Nações Unidas - ONU prevalece o entendimento de que há grupos marginalizados ou vulneráveis que demandam especial proteção dos Estados. Com efeito, no campo dos direitos humanos, há uma área vasta dedicada a certos grupos marginalizados, incluindo os povos indígenas, as minorias étnicas, os refugiados, os trabalhadores migrantes e os pobres. Sendo assim, um regime especial vem sendo desenvolvido para certos grupos nos últimos anos no âmbito da ONU, como exemplo, a Declaração e Programa de Ação de Viena impõe aos Estados a obrigação de criar e manter medidas para a proteção dos direitos dos grupos marginalizados (UNITED NATIONS, 2017). Compartilhando tal entendimento, Andorno (2016) afirma que no discurso dos direitos humanos o termo "vulnerabilidade" é usado para indicar a condição de suscetibilidade acrescida de determinados indivíduos ou grupos de serem feridos ou de sofrerem danos, tais como, crianças, mulheres, pessoas idosas, pessoas com deficiência ou pessoas pertencentes a grupos religiosos ou étnicos minoritários. Desse modo, os direitos humanos, por meio de normativas e órgãos de monitoramento, conferem diferencial tratamento a pessoas que são mais vulnerável ao abuso ou à discriminação, o que não lhes confere uma posição privilegiada, na medida em que o tratamento diferencial objetiva tão somente que possam usufruir os mesmos direitos (ANDORNO, 2016).

Embora Andorno (2016) sublinhe a importância do conceito de vulnerabilidade para o campo dos direitos humanos, sustenta que o fundamento normativo dos direitos humanos é a dignidade humana, com base na ideia de que tais direitos derivam de dignidade intrínseca de todas as pessoas, que não consiste numa condição acidental dos seres humanos. Ao passo que a vulnerabilidade é uma "condição" dos direitos humanos e não seu "fundamento", na medida em que a vulnerabilidade compartilhada é um fato que, por si só, não tem efeito normativo, assim, tal fato apenas se torna normativamente expressivo quando se assume que todas as pessoas detêm um valor inerente. Desse modo, a dignidade e a vulnerabilidade humanas são relevantes para o 
reconhecimento dos direitos humanos, mas desempenham papeis distintos, conseguintemente, os direitos humanos resultam de um fator normativo, o valor intrínseco da pessoa, e outro factual, o reconhecimento da fragilidade e da suscetibilidade de dano dos seres humanos (ANDORNO, 2016). Subsequentemente, passa-se ao emprego do aporte teórico sobre vulnerabilidade e direitos humanos ao campo dos cuidados em saúde, particularmente à condição de paciente.

\section{VULNERABILIDADE DO PACIENTE SOB A ÓTICA DOS DIREITOS HUMANOS}

Os Direitos Humanos dos Pacientes são um ramo do Direito Internacional dos Direitos Humanos, que abarcam o conjunto de convenções, pactos, declarações internacionais em matéria de direitos humanos; e a jurisprudência internacional construída pelos órgãos de monitoramento dos direitos humanos da ONU, do Sistema Europeu de Proteção dos Direitos Humanos, do Sistema Interamericano de Direitos Humanos e do Sistema Africano de Proteção dos Direitos Humanos. Dessa forma, nota-se que os Direitos Humanos dos Pacientes, enquanto ramo de uma disciplina específica, o Direito Internacional dos Direitos Humanos, é essencialmente internacional, na medida em que os direitos humanos dos pacientes são aqueles previstos em documentos internacionais adotados no âmbito de organismos internacionais (ALBUQUERQUE, 2016). Nessa direção, os Direitos Humanos dos Pacientes compartilham com o Direito Internacional dos Direitos Humanos o princípio da dignidade humana, consensualmente reconhecido como seu princípio-matriz (ANDORNO, 2014). Os direitos humanos previstos em normas internacionais são aqueles que se inserem no contexto dos cuidados em saúde dos pacientes, quais sejam: direito à vida; direito a não ser submetido à tortura, nem a tratamentos cruéis, desumanos ou degradantes; direito à liberdade e segurança pessoal; direito ao respeito à vida privada; direito à informação; direito de não ser discriminado; direito à saúde (ALBUQUERQUE, 2016).

Os Direitos Humanos dos Pacientes se alicerçam em princípios, dentre eles o princípio da autonomia relacional (ALBUQUERQUE, 2016), que se entrelaça com a ideia de vulnerabilidade. Embora o referencial dos Direitos Humanos dos Pacientes confira especial peso à autonomia do paciente, que é exercida mediante escolhas pessoais, concomitante, não o concebe como ser atomizado, apartado de suas relações pessoais e contextos de vida, assim como da sua condição de vulnerabilidade específica, expressada na sua dependência incrementada em relação aos outros, familiares, cuidadores e profissionais de saúde. Desse modo, a autonomia adotada neste estudo embasa-se na proposta de autonomia reconfigurada, elaborada por Pelluchon (2016). Essa autonomia considera a competência do indivíduo para viver sua própria vida, conforme seus interesses, desejos e crenças (EDOZIEN, 2015), o que não se atrela necessariamente à sua capacidade cognitiva (PELLUCHON, 2016). Sendo assim, adota-se neste estudo uma forma de autonomia que ultrapassa o conceito legal tradicional, porquanto o sujeito não é reduzido às suas incapacidades cognitivas, logo, são consideradas outras dimensões humanas, como seus 
desejos e valores. Mesmo quando se trata de paciente com severa deficiência cognitiva, como pacientes com Alzheimer, a autonomia, sob esse prisma, continua fazendo sentido. Com efeito, a ausência de competência cognitiva não deve conduzir imperiosamente à negação da autonomia do paciente, desse modo, o modelo de autonomia fundado na capacidade cognitiva há que ser reconfigurado com vistas a expressar primeiramente a capacidade do sujeito de "ter desejos e valores" (PELLUCHON, 2016), o que não é afetado pela deficiência ou restrição cognitiva, ou pela demência.

Assim, se, por um lado, a vulnerabilidade universal se atrela à interdependência subjetiva dos seres humanos, por outro, as pessoas não são igualmente dependentes em todos os momentos de sua vida, por óbvio, a dependência de uma criança que acaba de nascer ou de um paciente acamado é diferenciada, na medida em que sua sobrevivência depende diretamente da ação ou inação de seu cuidador. O fato de se estar enfermo desvela a precariedade da vida, pois a coloca em risco em razão de fator externo e incontrolável para o doente, como afirma Butler (2015, p.53), "nenhuma quantidade de vontade ou riqueza pode eliminar as possibilidades de doença ou de acidente para um corpo vivo". No mesmo sentido, Turner (2006, p.29) assinala que a vulnerabilidade humana traz à tona o fato de que nosso corpo é perecível, pois detém uma "orgânica propensão à doença e à moléstia, que a morte e o morrer são inescapáveis, que o envelhecimento dos corpos está sujeito à deficiência e ao enfraquecimento".

O cuidado do paciente pelo profissional de saúde traduz a dependência humana de modo acentuado, na medida em que essa interação é condição de sobrevivência do paciente, bem como é essencial, em muitas situações, para que o paciente tenha suas necessidades básicas atendidas, como comer ou tomar banho (ANDORNO, 2016), acarretando-lhe uma condição de vulnerabilidade particular. Como enfatiza Herring (2016), o cuidado em saúde produz vulnerabilidade, estando ambos imbricados, o que é amplificado pela significativa dependência do paciente em relação à equipe medica quanto ao seu diagnóstico, prognóstico e tratamento (ANDORNO, 2016).

Além da relação de cuidado acarretar vulnerabilidade acrescida e da doença por si mesma submeter o paciente à condição de fragilidade singular, a relação assimétrica entre paciente e profissional de saúde também concorre para sua condição particular de vulnerabilidade. Com efeito, há uma distância entre o paciente e o profissional de saúde na medida em que essa relação se encontra usualmente construída como conexão entre aquele que padece e outro, estranho, que tem o poder de the curar. Esse distanciamento pode ser aumentado ou mitigado de diversas formas, como por meio da linguagem usada pelo profissional, da forma como toca o paciente ou mesmo como o olha desse modo, quando o profissional faz uso de seu conhecimento técnico para demonstrar seu poder, afasta o paciente e impede a construção de "um solo comum no qual possam entender-se e isto é o diálogo, o único capaz de o instaurar" (GADAMER, 2009). Quando a distância entre o paciente e o profissional é 
aumentada, isso repercute diretamente em sua vulnerabilidade, porquanto o paciente se sente diminuto em face daquele que é detentor do saber científico sobre a sua doença.

Em síntese, constata-se que a vulnerabilidade específica do paciente se fundamenta em três aspectos: a) a doença que the afeta corporal e mentalmente; b) a assimetria da relação entre o paciente e o profissional de saúde; c) o fato de se encontrar numa relação de cuidado, ou seja, de forte dependência do outro. Nesse sentido, sublinha-se a assertiva de Pellegrino (apud ANDORNO, 2016, p. 259): "a pessoa doente é particularmente dependente, ansiosa, vulnerável e em estado passível de exploração. A pessoa doente é obrigada a desnudar sua fraqueza, comprometer sua dignidade, e a revelar suas intimidades corporais e mentais".

Em consonância com a posição sustentada por Herring (2016), o uso dos direitos humanos dos pacientes não deve demarcar espaços individuais de modo a fomentar uma relação contenciosa entre as partes do cuidado em saúde, mas sim serem empregados como instrumentos propulsores de laços comunitários e intersubjetivos. Isso porque os direitos humanos são entendidos como meio de aplacar a precariedade da vida e de proteger os seres humanos de vulnerabilidade intrínseca, sendo assim, a própria ideia de direitos humanos se conecta com o fato de que os seres humanos convivem, interagem e constroem laços. Portanto, não se sustenta a ideia de que se colocar em prol dos direitos humanos dos pacientes significa conceber o indivíduo apartado de suas relações.

O reconhecimento da vulnerabilidade intrínseca do paciente não condiz ao entendimento de que possui menos autonomia para decidir sobre sua própria vida ou corpo. Como enfatizado por Albuquerque (2016), a condição de paciente é paradoxal pois, concomitante, se encontra numa situação de vulnerabilidade aumentada, mas desempenha um papel central em seu cuidado e tratamento. Desse modo, sua vulnerabilidade não deve ser utilizada para the negar participação ou o protagonismo no processo de tomada de decisão sobre seu cuidado. Conforme pontua Herring (2016) há que se ter cautela para que o reconhecimento da vulnerabilidade do paciente não o transforme em sujeito passivo da relação de cuidado, sem papel operante, portanto vulnerabilidade não significa "deficiência, ausência de capacidade ou competência" (HERRING, 2016, p. 21). Nesse sentido, a vulnerabilidade do paciente não há que ser entendida como um argumento para justificar o paternalismo médico ou o estatal, isto é, a assunção de que o paciente é vulnerável não ampara a adoção de medidas coercitivas ou de "mecanismos de controle social" (BROWN apud HERRING, 2016, p.32).

Partindo do conceito de autonomia reconfigurado pela vulnerabilidade, infere-se que deficiências ou comprometimentos da capacidade cognitiva do paciente, como sua demência, não consiste em motivo isolado para negar-lhe o exercício de seu direito à privacidade ou à liberdade. Por exemplo, o paciente com vulnerabilidade específica há que ser protegido de modo a evitar-lhe dano, assim, tendo em conta tal paradoxal condição, há que se balancear a autonomia do paciente e sua proteção, que deve ser vista como um meio de assegurar o exercício da 
primeira (HERRING, 2016). Com efeito, a proteção do paciente há que se dar, no plano concreto, por meio do pleno exercício de seu direito à informação e privacidade, de modo a lhe assegurar participação no processo de tomada de decisão, sem descuidar de sua condição particular de fragilidade. Conforme pontua Andorno (2016), leis que asseguram o direito de escolha do paciente, por meio do qual exerce sua autonomia, minoram a vulnerabilidade do paciente decorrente da relação assimétrica travada com o profissional de saúde.

No plano prático, há uma longa estrada a ser percorrida com o intuito de se ter a incorporação da autonomia reconfigurada no cotidiano dos cuidados em saúde. A despeito de se reconhecer a importância de legislações que fixem o direito à privacidade do paciente e ao exercício de sua autonomia, a educação, que compreende a formação de profissionais de saúde e sua capacitação, é o principal meio para estimular uma visão nova do paciente e de seu papel no cuidado em saúde. Desse modo, este artigo traz à tona, com o escopo tão somente de apresentar uma forma de implantar as ideias ora abordadas, a intitulada "educação ética", que consiste numa educação em padrões morais que permitam o reconhecimento da vulnerabilidade própria e a do outro, bem como dos meios socialmente construídos para nos proteger, como os direitos humanos. Com efeito, a educação ética não irá transformar por si só os cuidados em saúde, mas é um aspecto fundamental para se promover um novo comportamento profissional quanto ao paciente. Desse modo, nas Faculdades de Medicina, Enfermagem e de outras profissões de saúde, é fundamental que haja um ensino que promova a identificação do profissional com o paciente, contrariamente a posturas que desumanizam o paciente, por meio da sua identificação numérica ou apelidos pejorativos. A "educação moral", ora sustentada, há que ser inserida nas disciplinas de Bioética ou de Ética Médica, fundada nos Direitos Humanos dos Pacientes, enquanto instrumental teórico-prático apto a criar uma moral compartilhada na esfera dos cuidados em saúde, alicerçada em afetos e sentimentos. Importa enfrentar a ideia amplamente compartilhada na comunidade médica que apenas os processos naturais importam para tratar o paciente, ampliando o conhecimento médico com vistas a incluir "o conhecimento da pessoa humana, das relações das pessoas entre si, de seus laços mútuos e das pressões e limitações que exercem entre si faça parte do conhecimento médico" (ELIAS, 2001, p.95).

A fim de demonstrar a especial proteção que se deve oferecer ao paciente idoso, enquanto titular de direitos pretende-se, a partir da análise de casos de ofensas a direitos humanos de pacientes idosos, discutir a situação de vulnerabilidade do paciente idoso a partir da jurisprudência da Corte Europeia de Direitos Humanos.

\section{OS DIREITOS HUMANOS DO PACIENTE IDOSO A LUZ DA JURISPRUDÊNCIA DA CORTE EUROPEIA DE DIREITOS HUMANOS}

Este tópico trata dos direitos humanos dos pacientes idosos, em razão do entendimento de que o paciente idoso, em decorrência de sua dupla vulnerabilidade, a causada pela doença e a que é agravada pela idade, 
é merecedor de atenção diferenciada e de uma especial proteção, particularmente na esfera dos cuidados em saúde. Exemplificando, inspeção realizada em 100 hospitais da Inglaterra, entre março e junho de 2011, para verificar os padrões de dignidade no tratamento e nutrição de pacientes idosos apurou que dois hospitais apresentavam padrões inaceitáveis de risco aos pacientes idosos; menos da metade (45 hospitais) atingia os padrões mínimos exigidos para alimentação ou tratamento digno; trinta e cinco hospitais satisfaziam os dois requisitos, mas necessitavam de melhorias para que pudessem oferecer cuidados de qualidade aos pacientes idosos (CARE QUALITY COMMISSION, 2011). Dentre as violações relatadas no documento foram ressaltados tratamento inadequado e desrespeitoso por parte dos profissionais de saúde; imposição de condutas aos pacientes e ausência de diálogo; os chamados dos pacientes idosos eram ignorados por horas e não era oferecida assistência às necessidades mais básicas, como comer, beber ou ir ao banheiro; as cortinas não eram fechadas de forma a garantir a privacidade do paciente; falta de higiene básica ao paciente idoso. Há muito os pacientes idosos são infantilizados ou ignorados em hospitais e não raro deixam de receber adequada hidratação e nutrição, bem como são desrespeitados em sua dignidade e discriminados em razão da idade (HERRING, 2016).

A Corte Europeia de Direitos Humanos e tribunais da Inglaterra preconizam que existem direitos especiais para adultos vulneráveis e, consequentemente, há especial obrigação do Estado de protegê-los contra abusos, ou seja, a obrigação do Estado aumenta quando se trata de sujeito vulnerável (HERRING, 2016). Considerando a vulnerabilidade especifica do paciente idoso, neste item do artigo serão examinadas decisões proferidas pela Corte Europeia de Direitos Humanos com o intuito de verificar como uma corte de direitos humanos faz incidir na prática os Direitos Humanos dos Pacientes sob o enfoque da vulnerabilidade, da proteção e respectiva conjugação com o respeito à autonomia.

No caso Volintiru v. Itália (Petição n. 8530/08), verifica-se a importância de se envolver o Estado em questões de ofensa a direitos humanos de paciente idoso e que, eventualmente, não foram conduzidas de forma satisfatória pela justiça local. No caso, relata-se que, em 2007, uma senhora de 85 anos foi levada ao hospital em estado crítico de saúde. Cerca de um mês após o fato, os médicos decidiram que ela deveria ter alta do hospital, em razão de pequena melhora, mesmo estando ainda em estado de saúde grave. Poucos dias após a alta hospitalar, ela foi levada para o pronto-socorro em coma e morreu posteriormente. A filha da paciente apresentou queixa contra o hospital, alegando que a mãe não recebeu todo o tratamento necessário para proteger sua vida, também afirmou que as más condições do hospital causaram a infecção que levou à morte de sua mãe, bem como frisou a falta de investigação eficaz por parte das autoridades sobre o assunto. A peticionante denunciou, especificamente, as más condições de higiene do hospital; a utilização de um canapé quebrado e sujo, onde sua mãe era colocada durante longo tempo sem roupa e sem higienização; os pés da mãe, cheios de escaras, eram apoiados em repouso de pé sujo; leitos quebrados e enferrujados; quarto sujo e que não era lavado ou desinfetado; os leitos das pessoas que 
morriam na mesma enfermaria não eram devidamente limpos; foi arrancado pela equipe de saúde, e não por dentistas, o último dente de sua mãe, que servia de apoio para sua prótese dentária; era utilizada sempre a mesma seringa de alimentação, que era limpa apenas com água; os profissionais de saúde usavam a mesma luva para aplicar medicação oral e tirar sangue de todos os pacientes; e os testes glicêmicos eram feitos com a mesma agulha.

A partir da verificação de ocorrência de possíveis violações de direitos humanos, a Corte comunicou o pedido ao Governo italiano em março de 2013, que foi questionado acerca da violação dos seguintes direitos: direito à vida; tratamento desumano ou degradante; desrespeito pela vida privada. Verifica-se que se tratava de paciente idosa, com vulnerabilidade acrescida, cujo estado crítico de saúde motivou a condução do tratamento de maneira desidiosa e desrespeitosa, tendo sido desconsideradas as condições particulares da paciente. De fato, é possível constatar no caso em apreço ofensas a Direitos Humanos dos Pacientes, pois as más condições de cuidados oferecidos mostraram-se incompatíveis com a situação crítica de fragilidade da paciente, que foi desrespeitada em sua privacidade (exposição de seu corpo e falta de higienização), não foi consultada sobre os procedimentos levados a cabo pelos profissionais da saúde (como a extração do único dente), foi submetida a ambiente precário de cuidados (sujeira e ausência de assepsia do material), sem qualquer apoio psicológico ou demonstração de preocupação com a compreensão de seus anseios, valores e vontades diante da doença. Configura-se, aqui, típico exemplo de assimetria nas relações de cuidado e de utilização da vulnerabilidade acrescida da paciente para negar-lhe o direito ao exercício da autonomia. Ainda que a paciente estivesse comprometida emocional e cognitivamente para tomar decisões sobre seus cuidados, verifica-se que também à filha da paciente foi obstado o direito de participar das decisões terapêuticas, de oferecer o apoio necessário à sua mãe e de exigir do hospital e dos respectivos profissionais da saúde a observância de questões básicas de cuidados, higiene e segurança da paciente. Mesmo tratando-se de paciente com comprometimento da capacidade cognitiva, o que se espera de uma cultura de cuidados voltada para o respeito aos direitos humanos é que haja empenho dos envolvidos no sentido de potencializar as capacidades do paciente idoso, respeitar suas limitações e resguardar sua dignidade. Conforme antes abordado, os direitos humanos não concebem o indivíduo apartado de suas relações, razão pela qual a par de conferirem peso importante à autonomia do paciente, reconhecem que, devido à sua vulnerabilidade, faz-se necessário o estabelecimento de laços comunitários e intersubjetivos que o protejam de suas vulnerabilidades específicas.

É dever dos profissionais da saúde e dos familiares contribuir para o desenvolvimento da autonomia do paciente idoso, incentivando-o a tomar decisões e a ter iniciativa nas questões relativas à higiene, saúde, ocupação, relacionamentos, mesmo quando se observa a diminuição das capacidades e habilidades da pessoa idosa (SAQUETTO et al., 2013). Observa-se que o não envolvimento do paciente idoso no tratamento tem efeito contrário ao esperado, pois chancela uma sensação de incapacidade e de apatia prejudiciais ao próprio processo 
de melhora. Autores chamam a atenção para o fato de que o respeito à autonomia do paciente idoso deve atentar para a maneira peculiar que cada um tem de apreender o contexto social que o envolve, de fazer escolhas baseadas em seus valores, de agir de acordo com seus princípios, crenças e visão de mundo, razão pela qual pregam a necessidade de mudança na postura paternalista e hipocrática enraizada na formação do profissional de saúde (VISENTIN, LABRONICI e LENARDT, 2007). Com efeito, o respeito à autonomia impulsiona mudanças nas relações de cuidados, pois diminui a assimetria das relações, estimula um processo de troca, de compartilhamento e de cumplicidade, a partir do estabelecimento de uma rede de proteção em que o paciente, reconhecido em sua fragilidade, apoiado pelos seus afetos e respeitado em suas decisões sobre tratamentos pelos profissionais da saúde, sente-se respaldado, amparado e mais disposto a participar da terapêutica. Nesse ponto, a tomada de posição da Corte Europeia junto ao Governo Italiano mostrou-se pertinente e adequada no sentido de apurar violações e resguardar direitos humanos de paciente.

O direito à liberdade e à segurança pessoal dos pacientes é pouco debatido e os casos de ofensa a tal direito são mais comumente apreciados pelos Tribunais internacionais quando se trata de paciente com transtorno mental. Neste artigo, a partir da análise de um caso de retenção involuntária de pessoa idosa pretendese discutir o direito em comento para que reflexões sobre o tema possam conferir ao assunto maior visibilidade, bem como influenciar positivamente os julgamentos que envolvem a matéria. O caso H.M. v. Suíça (petição n. 39187/98) envolve queixa de pessoa idosa sobre a ilegalidade da sua privação de liberdade, decorrente de sua internação compulsória por alegada negligência em seus cuidados de saúde. No julgamento, o Tribunal declarou que não houve violação do direito à liberdade e à segurança pessoal, concluindo que a colocação da recorrente em instituição de cuidados não constituía privação de liberdade, mas tinha sido uma medida tomada pelas autoridades competentes no interesse da própria requerente, a fim de lhe proporcionar os cuidados médicos necessários e condições de vida e de higiene satisfatórias. O Tribunal observou, em especial, que a recorrente teve a oportunidade de receber cuidados na sua própria casa, mas que ela e o seu filho se recusaram a cooperar. Posteriormente, foi alegado pela Corte que as condições de vida da paciente deterioraram-se de tal forma que as autoridades decidiram tomar as medidas que julgaram adequadas. A comissão de apelações examinou as circunstâncias do caso e decidiu que a instituição de saúde em questão, que se encontrava numa área familiar para a requerente, poderia prestar-lhe os cuidados necessários e que a paciente, após ter sido para lá deslocada, tinha concordado em ficar.

O direito à liberdade refere-se à proibição de restrição física, e a segurança pessoal diz respeito à preservação da integridade física e mental do paciente (ALBUQUERQUE, 2016). O direito à liberdade, no entanto, não é absoluto, pois existem normas, nacionais e internacionais, que preveem sua restrição, como em casos de possibilidade de propagação de doenças infecciosas, alienação mental, alcoolismo ou uso de drogas 
(EHRC, 1950), bem como há situações em que a privação de liberdade é necessária para proteger o paciente de sério dano ou para impedir danos a outrem (HUMAN RIGHTS COMMISSION, 2014). Ainda que a legislação atribua às entidades públicas ou privadas autorização para restringir a liberdade individual, persiste a obrigação do Estado em assegurar que tal procedimento ocorra sem abusos e em observância estrita às normas de direitos humanos, para que não se configure interferência arbitrária ou ilegal. A simples possibilidade de causar dano a si próprio ou a terceiro não é suficiente para autorizar uma retenção involuntária. Com efeito, o ato de privação da liberdade de alguém é, por si só, uma conduta gravosa para o paciente, razão pela qual deve ser necessária, proporcional, ocorrer apenas em caso de risco de deterioração da saúde do paciente e se não houver outro meio menos restritivo de direitos para o caso específico daquele paciente (ALBUQUERQUE, 2016).

Herring (2016) alerta para a necessidade de se estabelecer um ponto de equilíbrio entre o dever do Estado de proteger pessoas vulneráveis e o direito ao respeito à autonomia quando o vulnerável não quer a proteção oferecida pelo Estado. Sem adentrar em discussão acerca de quais seriam os limites razoáveis à atuação do Estado na proteção de pessoas vulneráveis, salienta-se que uma corte internacional que visa resguardar os direitos de pacientes idosos deve atentar-se, em seus julgamentos, além dos aspectos legais, à conjugação de outros elementos de mesma importância, tais como a proteção da vulnerabilidade e o respeito à autonomia. Partindo-se do pressuposto de que a privação da liberdade é uma medida extrema, o julgamento do caso H.M. v. Suíça, ora em análise, suscita questionamentos acerca de sua adequação. Ainda que se alegue que o intuito das autoridades era preservar a vida, a saúde e a integridade pessoal de pessoa idosa em situação de negligência, importante ressaltar que se tratava de pessoa com capacidade cognitiva preservada e que resistiu à determinação de ser internada compulsoriamente. Embora se mostre louvável a iniciativa pública de assegurar a saúde e condições mais dignas de vida às pessoas idosas, a simples idade avançada não justifica a ingerência em sua autodeterminação. Mesmo que a pessoa apresente condições de saúde frágil, agravada pelas intercorrências da idade, os profissionais de saúde e as autoridades estatais devem usar de muita cautela para reter involuntariamente alguém, pois tais restrições podem caracterizar ofensa a direitos humanos do paciente. Assim, ainda que o caso apresentado envolva pessoa vulnerável com problemas de saúde e em condições precárias de cuidados, passível, portanto, de proteção do Estado, nota-se que a paciente tinha por preferência morar e ser cuidada por seu filho e manifestou recusa ao tratamento que lhe foi imposto. Mesmo que haja algum tipo de dependência, a condição de fragilidade da pessoa idosa não pode ser usada como justificativa para mitigar sua vontade quanto à forma de tratamento de saúde, pois vulnerabilidade não significa perda da autonomia. Nesse sentido, quando se desrespeita a vontade do paciente idoso e o submete a cuidados de forma autoritária, tal desrespeito reflete em sua autonomia e, consequentemente, em sua qualidade de vida, fazendo com que o paciente adote uma postura passiva e pouco questionadora. Dessa forma, a atuação do Estado é passível de gerar dano ao paciente idoso, pois extrapola o intuito de proteção e 
assume feições paternalistas, infringindo, assim, regras éticas, legais e morais (CUNHA et al., 2012).

Importante ressaltar que o julgamento do caso H.M. v. Suíça deu-se em 2002 e é possível verificar uma evolução jurisprudencial por parte da Corte Europeia desde então. Em recente julgado, a Corte Europeia de Direitos Humanos decidiu que houve violação ao direito à liberdade de pessoa com transtorno mental e que foi institucionalizada sem o seu consentimento, apenas com base na autorização de seu curador judicial (Cervenka v. República Tcheca, outubro de 2016). Conforme anteriormente tratado, existe uma maior incidência de casos de restrição de liberdade de pacientes com transtorno mental do que casos de restrição de liberdade de paciente idoso. Com base neste caso, busca-se chamar a atenção para o fato de que os casos de internação compulsória devem ser rigorosamente analisados, levando-se em conta a presença do risco de morte ou dano iminente para o paciente ou terceiros. A nova tendência jurisprudencial da Corte Europeia que sinaliza em favor da não restrição da liberdade dos pacientes mostra-se em sintonia com os direitos humanos e configura-se importante instrumento para impulsionar os Estados na revisão de sua legislação e políticas públicas, mediante a busca de programas estatais alternativos, menos restritivos e gravosos à liberdade e à segurança pessoal dos pacientes.

No que diz respeito ao direito a não ser submetido à tortura nem a penas ou tratamentos cruéis, desumanos ou degradantes, a jurisprudência da Corte tem se mostrado de grande valia na proteção de direitos humanos de pacientes em situações diversas, como se nota no caso Sawoniuk v. Reino Unido (petição n. 63716/00), em que se apuraram condições de detenção agravadoras da condição de saúde do requerente, capazes de configurar tratamento cruel, desumano ou degradante. No processo em questão, o requerente, condenado a prisão perpétua, queixou-se de que sua idade avançada (79-80 anos), problemas de saúde e insuficiência de tratamento na prisão tornaram sua detenção uma dificuldade excepcional. Embora o pedido do reclamante não tenha sido admitido por questões formais (não esgotamento dos recursos internos), as ponderações apresentadas pelo Tribunal demonstram nítido propósito de proteção de direitos humanos de paciente idoso. Segundo o Tribunal, embora não haja proibição legal de detenção em prisão de pessoas com idade avançada, a incapacidade de prestar os cuidados médicos necessários aos prisioneiros pode constituir tratamento desumano e os Estados têm a obrigação de adotar medidas para salvaguardar o bem-estar das pessoas privadas de liberdade. O Tribunal frisou, entretanto, que, para atingir o limiar do direito de não sofrer penas ou tratamentos desumanos ou degradantes, a gravidade dos maus-tratos ou negligência deve ser devidamente contextualizada, ou seja, devem-se levar em conta os elementos particulares do caso, tais como a idade, o estado de saúde da pessoa, a duração e a natureza do tratamento e os seus efeitos físicos ou mentais.

De fato, a configuração de ofensa a direito humano de paciente com base em tratamento cruel, desumano ou degradante depende das circunstâncias do caso. Entretanto, em se tratando de paciente em condições de vulnerabilidade acrescida, qualquer nível de abuso é capaz de atingir patamares inquestionáveis. Ou 
seja, quando o abuso é cometido contra pessoa vulnerável, maior a possibilidade de configuração de ofensa a direitos humanos. No caso específico tratado, o prisioneiro em questão é pessoa idosa que se encontra em condições precárias de saúde, ou seja, trata-se de pessoa portadora de vulnerabilidades agravadas pelo ambiente, idade e doença, que tem direito, portanto, de ter suas especificidades consideradas e a receber especial atenção do Estado. Conforme frisado por Andorno (2016), não se visa ofertar posição privilegiada a pessoa vulnerável, mas garantir que usufrua de iguais direitos.

A partir de situações concretas vivenciadas por pacientes idosos buscou-se, por meio da análise de decisões proferidas pela Corte Europeia de Direitos Humanos, identificar e discutir direitos humanos de um grupo específico de pessoas vulneráveis, no contexto dos cuidados em saúde. Verifica-se do presente estudo que a jurisprudência voltada aos cuidados em saúde da pessoa idosa tem como missão mitigar a vulnerabilidade acrescida, garantir o exercício da autonomia, bem como conferir segurança a esse grupo populacional, resguardando, assim, os Direitos Humanos dos Pacientes.

Constatou-se que os pacientes idosos estão sujeitos a violações de direitos humanos diversos, tais como relacionamentos abusivos, infantilização, desrespeito à autonomia, discriminação em razão da idade, violências físicas e emocionais, e, portanto, demandam uma atitude ativa de intervenção do Estado para que possam ter condições de vida. A jurisprudência internacional apresenta-se como importante mecanismo de proteção de direitos dos pacientes idosos, na medida em que reconhece as vulnerabilidades específicas desse grupo, assente que o paciente idoso não ocupa simples posição de receptor de cuidados e que, a despeito de sua enfermidade, tem condições de exercer sua autonomia e participar ativamente de seu processo terapêutico. Os julgamentos proferidos pela Corte Europeia trazem à tona os problemas vivenciados por pacientes idosos, o que torna tal grupo visível e, assim, impulsiona a estruturação de redes específicas de proteção e de mitigação da vulnerabilidade acrescida que é própria dessa faixa etária.

\section{CONSIDERAÇÕES FINAIS}

As sociedades humanas em seu percurso histórico criam normas, ideias e sentidos que as possibilitem manter os agrupamentos coesos, por meio de instrumentos inventados para lidar com as pulsões de violência e agressividade e proteger os mais frágeis. Os direitos humanos podem ser considerados assim, como uma ideia inventada com o intuito de mitigar a vulnerabilidade e refrear as pulsões destrutivas. Na esfera dos cuidados em saúde, tendo em conta que o paciente é, com certa variação de grau, sempre mais vulnerável que uma pessoa não enferma, os direitos humanos têm esse caráter de instrumento protetivo. Contudo, a proteção do paciente não caminha junto com medidas paternalistas ou coercitivas, ao revés, em regra, proteção implica autonomia, direito do paciente de se manifestar, de participar e de se ver integrado aos seus cuidados, porquanto não se protege um 
paciente considerando-o incapaz, incompetente ou desqualificado. A proteção do vulnerável atrela-se à sua consideração como uma pessoa repleta de desejos e emoções, que serão levados em conta no seu processo terapêutico, a despeito de sua capacidade cognitiva. No caso do paciente idoso, o sentido social construído em torno de sua incompetência e desqualificação para decidir é maior, ainda se percebe a pessoa idosa como frágil e por isso alguém a ser amplamente protegido. Sob a ótica dos Direitos Humanos dos Pacientes, há que se harmonizar o reconhecimento da vulnerabilidade acrescida do paciente idoso com a imperiosidade de respeitar suas escolhas, desejos e emoções, desqualifica-los, em razão de ideias que sustentam sua incapacidade cognitiva decorrente dos efeitos do envelhecimento sobre o cérebro, não é aceitável do ponto de vista dos direitos humanos. Por fim, reconhece-se que essa alteração de sentido social demanda árduo trabalho na formação de profissionais de saúde, de modo que seus estudos de graduação também contemplem uma compreensão ética do outro, mediante, dentre outras ferramentas teórico-práticas, a incorporação da linguagem dos direitos humanos ao seu arcabouço profissional.

\title{
HUMAN RIGHTS OF PATIENTS AND VULNERABILITY: THE ELDERLY PATIENT IN LIGHT OF THE JURISPRUDENCE OF THE EUROPEAN COURT OF HUMAN RIGHTS
}

\begin{abstract}
This article aims to examine the interfaces between vulnerability and human rights, particularly the correlation of the first concept with the Human Rights of Patients, understood in this study as a theoretical-normative framework that deals with the application of human rights norms in healthcare sphere. In addition, I have intended to outline the theoretical contours of the correlation between human rights and vulnerability, with particular concern with patients, and I have also investigated how a human rights court applies such rights in practice considering the specific vulnerability of the elderly patient. Concerning the methodological perspective, it is a bibliographical and documentary research. It was concluded that the recognition of the increased vulnerability of the elderly patient should be balanced with respect for their choices, desires and emotions; it is not acceptable from human rights approach disqualifying elderly patient's choices, desires and emotions because of their cognitive incapacity due to the effects of aging on the brain. Finally, it is recognized that the modification of this social sense demands hard work related to training of health professionals in order to undergraduate studies contemplate an ethical view of the other, by incorporating the language of human rights into their professional framework.
\end{abstract}

Keywords: Human Rights; Vulnerability; Patient; Elderly Person.

\section{REFERENCIAS}


ALBUQUERQUE, Aline. Direitos humanos dos pacientes. Curitiba: Juruá, 2016.

ANDORNO, Roberto. Is vulnerability the foundation of Human Rights? In.: MASFERRER, ANICETO; GARCÍA-SÁNCHEZ, EMILIO (editors). Human dignity of the vulnerable in the age of rights. Valencia: Springer, 2016. p. 257-272.

Human Dignity and Human Rights. In.: TEN HAVE, Henk A.M.J. and GORDJIN, Bert (Eds.). Handbook of Global Bioethics. Dordrecht: Springer, 2014. p. 45-57.

BUTLER, Judith. Quadros de Guerra: quando a vida é passível de luto: São Paulo: Civilização Brasileira, 2015.

CARE QUALITY COMMISION. Dignity and Nutrition for Older People, 2011. Disponível em <http://www.cqc.org.uk/content/dignity-and-nutrition-older-people-2\#2011>. Acesso em: 26 nov 2016.

CUNHA, J.X.P; OLIVEIRA, J.B.; NERY, V.A.S.; SENA, E.L.S.; BOERY, R.N.S.O, YARID, S.D. Autonomia do idoso e suas implicações éticas na assistência de enfermagem. Saúde em Debate. Rio de Janeiro, v. 36, n. 95, p. 657664, out./dez. 2012.

ECHR. Convenção Europeia de Direitos Humanos. Convenção para a proteção dos direitos do homem e das $\begin{array}{llllll}\text { liberdades fundamentais, } & \text { art. } & 5^{\circ} \text {., } & 1950 . & \text { Disponível em }\end{array}$ $<$ http://www.echr.coe.int/Documents/Convention_POR.pdf>. Acesso em 03 dez 2016.

Factsheet - Elderly people and the ECHR Disponível em: <http://www.echr.coe.int/Documents/FS_Elderly_ENG.pdf>.Acesso em: 27 jan 2017.

EDOZIEN, LEROY C. Self-determination in health care. Surrey: Ashgate, 2015.

ELIAS, Norbert. A solidão dos moribundos. São Paulo: Zahar, 2001.

HERRING, Jonathan. Vulnerable adults and the law. Oxford: Oxford University Press, 2016.

HUMAN RIGHTS COMMISSION. General comment n. 35. Article 9: Liberty and security of person, 2014. Disponível

em: $<$ http://tbinternet.ohchr.org/_layouts/treatybodyexternal/Download.aspx?symbolno=CCPR\%2fC\%2fGC $\% 2 \mathrm{f}$ 35\&Lang=en $>$. Acesso em: 03 dez 2016.

GADAMER, Hans-Georg. O Mistério da Saúde: o cuidado da saúde e a arte da medicina. Lisboa: Edições 70, 2009.

GROVER, Anand. Estudio temático sobre el ejercicio del derecho a la salud de las personas mayores realizado por el Relator Especial sobre el derecho de toda persona al disfrute del más alto nivel posible de salud física y mental, Anand Grover. Disponível em: https://documents-ddsny.un.org/doc/UNDOC/GEN/G1 1/143/64/PDF/G1114364.pdf?OpenElement. Acesso em: 26 nov 2016.

PELLUCHON, CORINE. Taking vulnerability seriously: what does it change for bioethics and politics? In.: MASFERRER, ANICETO; GARCÍA-SÁNCHEZ, EMILIO (editors). Human dignity of the vulnerable in the age of rights. Valencia: Springer, 2016. p. 293-312.

SAQUeTTO M., SCHETTINO, L., PINHEIRO, P., SENA, E.L.S., YARID, S.D., GOMES FILHO, D.L. Aspectos bioéticos da autonomia do idoso. Rev. bioét. (Impr.). 2013; 21 (3): 518-24. 
TURNER, Bryan S. Vulnerability and Human Rights. Pennsylvania: Pennsylvania State University. 2006.

UNITED NATIONS. Part V. Rights of Vulnerable Groups with Disabilities. Disponível em: http://www.un.org/esa/socdev/enable/discom500.htm. Acesso em: 24 jan. 2017.

VISENTIN, A., LABRONICI, L., LENARDT, M.H. Autonomia do paciente idoso com câncer: o direito de saber o diagnóstico. Acta Paul Enferm, 20(4):509-13, 2007.

Trabalho enviado em 15 de fevereiro de 2017.

Aceito em 22 de maio de 2017. 